\title{
LIBERDADE DE GÊNERO: promovendo algumas fissuras na lógica heteronormativa
}

\author{
Thais Geraldo Oliveira de Aguiar * \\ Raquel Pereira Quadrado**
}

Resumo: Esse artigo resulta de uma pesquisa desenvolvida a partir de referenciais e produções decorrentes das contribuições do GEERGE, especialmente as da fundadora e pesquisadora Guacira Louro. A pesquisa teve como corpus de análise a série Liberdade de Gênero, exibida no canal GNT e teve como objetivo analisar as falas dos/as entrevistados/as na série acerca de suas vivências trans, problematizando sobre os atributos de gênero, o entrelaçamento existente entre gênero e sexualidade e as mídias como espaço de encontro e pertencimento. A série mostra em 10 episódios como se organizam as vidas de 14 pessoas trans que assumem a experiência de ter um gênero diferente do sexo anatômico, trazendo exemplos em que essas pessoas se inserem de forma bem-sucedida e feliz dentro da sociedade

Palavras chave: vivências trans; sexualidade; gênero.

GENDER FREEDOM:

promoting some cracks in the heteronormative logic

\begin{abstract}
This paper results from a research developed from referential and productions derived from GEERGE's contributions, specially the ones made by the founder and researcher Guacira Louro. The research had as corpus analysis the TV series "Liberdade de Gênero", exhibited in the GNT channel and aimed to analyze the speeches of the people interviewed in the series which were about their trans experiences, discussing gender attributes, the existing connection between gender and sexuality and the medias as a space of encounter and belonging. The series shows in 10 episodes how the lives of 14 trans people are organized considering they assumed the experience of having a different gender of their anatomical sex, bringing examples in which these people are placed in the society in a successful and happy way.
\end{abstract}

Key words: trans experiences; sexuality; gender.

Submissão 21-01-19 Aceite 26-01-19

\section{DELINEANDO A PESQUISA}

O Grupo de Estudos de Educação e Relações de Gênero (GEERGE) vem, desde o ano de 1990, constituindo-se como uma das principais instâncias no nosso país a formar pesquisadores/as e produzir pesquisas relacionadas a gênero, sexualidade, etnia, educação, em suas múltiplas e complexas articulações. Deste modo, o GEERGE desponta no cenário brasileiro e internacional como referência nos estudos de gênero, criando condições de possibilidade - no sentido foucaultiano - para que inúmeras pesquisas pudessem ser desenvolvidas. Com isso, tem contribuído para que outras formas de se olhar e se pensar as vivências e experiências de gênero e de sexualidade se façam possíveis. Esse artigo

\footnotetext{
* Mestre em Educação em Ciências pela Universidade Federal do Rio Grande - FURG

** Mestrado em Educação Ambiental pela Universidade Federal do Rio Grande - FURG (2006). Atualmente é professora da Universidade Federal do Rio Grande - FURG.
} 
apresenta uma dessas pesquisas, em que as contribuições teóricas do GEERGE, de modo especial as de Guacira Louro, possibilitaram lançar alguns olhares para as vivências narradas na série Liberdade de Gênero ${ }^{1}$, que constituiu o corpus de análise dessa pesquisa.

Vivemos em um tempo de constantes transformações culturais, suscitada por instâncias sociais que assumem em nossa cultura diversas formas de comunicação e informação. Nesse tempo de transformações, outras formas de ser e de viver os gêneros e as sexualidades têm emergido e estão sendo visibilizadas. Dentre essas, as vivências trans têm conquistado espaço nas mídias em geral, onde a temática da transexualidade, travestilidade e transgeneridade tem sido abordada em filmes, discutida em novelas, documentários e séries, problematizando a luta dessas pessoas por condições melhores para poderem viver como realmente elas são.

Uma das séries televisivas que trouxe essa abordagem foi Liberdade de Gênero, exibida no canal GNT. Na primeira temporada da série, que conta com 10 episódios, quatorze pessoas trans são entrevistadas. O primeiro episódio conta a história de Amanda, uma mulher transexual que se submeteu a cirurgia de redesignação sexual na Tailândia. O segundo episódio traz a história de Letícia Lanz, uma mulher transgênera, que após viver 50 anos em um corpo masculino inicia a transição de gênero. O terceiro episódio consta a história de Erick, que aos 19 anos descobriu que era possível fazer a transição de gênero e iniciou o seu processo para se tornar um homem transexual. O quarto episódio traz pessoas trans não binárias para narrarem suas trajetórias, são elas: Liniker, Lune, Jesse e Bennet. O quinto conta a história de Wallace, que se considera uma pessoa trans não binária que se aproxima do feminino. O sexto episódio traz a história de duas mulheres trans, Carol Marra e Glamour Garcia, ambas são atrizes e modelos. O sétimo episódio traz a história de Sillvio Lúcio, que se identifica como homem transexual. O oitavo episódio traz a narrativa de Márcia, uma travesti lésbica. O nono traz a história de Oliver, pessoa trans não binária e de Dani, mulher transexual que fez a cirurgia de redesignação sexual com a ajuda de seus amigos/as e alunos/as. E para terminar a primeira temporada da série, o décimo episódio conta a história de dois casais trans, Anderson e Helena, homem trans e mulher trans, que são pais biológicos do pequeno Gregório; e Patrick e Bárbara, que estão juntos há quase dois anos e são militantes da causa trans.

Diante desta breve apresentação dos/as entrevistados/as na série, dialogamos com a

\footnotetext{
${ }^{1}$ Disponível em https://globosatplay.globo.com/gnt/v/5408040/ Acesso em 20 de novembro de 2018.
} 
autora Guacira Louro, quando ela diz que vivemos "um tempo em que a diferença se multiplicou. Um tempo em que a verdade é plural". (2003, p. 09) A série Liberdade de Gênero foi ao ar pela primeira vez em 19 de outubro de 2016, no canal GNT. O diretor, João Jardim, percorreu do sul ao norte do país com a proposta de dialogar sobre a diversidade de gênero, trazendo histórias e identidades diferentes, onde as faixas etárias dos/as entrevistados/as variam de 19 a 64 anos.

Neste artigo, analisamos as falas dos/as entrevistados/as na série acerca de suas vivências trans, problematizando os atributos de gênero, o entrelaçamento existente entre gênero e a sexualidade, e as mídias como espaço de encontro e pertencimento.

\section{DIÁLOGOS TEÓRICOS}

Este artigo ancora-se no campo de teorização dos Estudos Culturais, em suas vertentes pós-estruturalista de análise. Este é caracterizado por ser "um campo de estudos onde diversas disciplinas se interseccionam no estudo de aspectos culturais da sociedade contemporânea" (ESCOSTEGUY, 2004, p. 137). Apoiamo-nos neste campo por entender que ele é potente para as pesquisas que analisam as relações imbricadas entre cultura e sociedade, articulando com os significados que problematizamos neste artigo a partir de nossas análises sobre as narrativas da série Liberdade de Gênero.

A autora Marisa Vorraber Costa afirma que a principal virtude dos Estudos Culturais “talvez seja a de começar a admitir que a inspiração possa advir de qualquer lugar, contribuindo para desfazer os binarismos tão fortemente aderidos às epistemologias tradicionais" (2004, p.14). Instigadas pela colocação da autora entendemos que o propósito do campo em questão não é chegar a "verdades" absolutas, ou definir o que é certo e errado,

porque a partir desta óptica os binarismos não dão conta das produções culturais deste mundo. Pesquisar com a lente dos Estudos Culturais, sob a perspectiva pós-estruturalista, é um convite a movimentar o pensamento, tecendo problematizações sobre os modos de ser e estar no mundo sem a pretensão de chegar a um ponto final sobre determinada "verdade". Conforme Costa: “A 'verdade' ou a 'realidade' são construções discursivas resultantes de epistemes situadas e datadas. Não há nada de transcendental aí. A verdade ou as verdades são coisas deste mundo, constituídas no seio de correlações de forças e de jogos de poder." (2004, p. 76) Assim, tomamos as verdades como produções culturais deste mundo que, portanto, podem ser resignificadas. 
Além disso, neste campo teórico, defende-se a ideia de que nada neste mundo antecede a cultura, sendo assim, somos sujeitos constituídos pela cultura de uma determinada época e lugar. Pensamos na cultura a partir de Hall (1997) compreendendo que esta é responsável pelas produções de sentidos que são compartilhados socialmente, que se configuram como um dar e receber significados, uma prática social.

Esse campo encarrega-se de estudar as produções culturais e se faz potente para a análise de uma série televisiva como a Liberdade de Gênero, porque entendemos que nela circulam pedagogias culturais que nos ensinam modos de ser e estar no mundo. As pedagogias culturais, de acordo com Veiga-Neto (2006), salientam como e quanto, fora dos espaços estritamente institucionalizados, se ensina, se aprende e se naturaliza determinadas verdades, visões de mundo e práticas sociais. Ou seja, neste campo entendemos que as aprendizagens não estão fixas ao espaço escolar e/ou acadêmico, mas o transcendem.

Conforme Constantina Xavier Filha (2014), olhar para as pedagogias culturais nos possibilita refletir sobre os discursos que vêm sendo produzidos na contemporaneidade e que, de certa maneira, vão produzindo nossas identidades. Ao olharmos para as pedagogias culturais expressas na série Liberdade de Gênero tecemos problematizações sobre como os discursos vão produzindo significados sobre a forma com que os sujeitos percebem e ou deveriam perceber seus corpos, seus gêneros e suas sexualidades, sem a pretensão de fazer algum juízo de valor sobre o que é certo ou o que é errado, mas, sim problematizar os “processos pelos quais as diferenças são produzidas através de relações de assimetria e desigualdade" (SILVA, 2007, p. 89).

Diante disso, percebemos a série Liberdade de Gênero como um artefato cultural importante para a discussão da diversidade dos gêneros e das sexualidades. Conforme a autora Guacira Louro, "a construção do gênero e da sexualidade dá-se ao longo de toda a vida, continuamente, infindavelmente" (2008, p. 18). Cabe aqui colocar, que entendemos os gêneros e as sexualidades como construções sociais, culturais, políticas e históricas que são atravessadas por relações de poder e não como algo que é dado e natural. Para Louro: "Se aceitarmos que o gênero não é natural, mas sim construído, estamos dando um passo para desfazer a conexão estreita entre sexo e gênero, e podemos começar a pensar que não há uma relação única e necessária entre o corpo de alguém e seu gênero.” (2017, p. 56) 
Esta relação de conexão entre o corpo e o gênero não faz sentido, sob a perspectiva que lançamos nossos olhares, porque além de entendermos que o gênero é uma construção cultural, entendemos que o sexo anatômico também ganhou significado culturalmente, visto que a anatomia é um conhecimento construído e não uma "verdade". Judith Butler nos desafia a pensar na construção cultural do gênero e do sexo quando coloca que “o gênero não está para a cultura como o sexo para a natureza; ele também é o meio discursivo/cultural pelo qual 'a natureza sexuada' ou 'um sexo natural' é produzido e estabelecido como 'pré-discursivo', anterior à cultura” (2017, p. 27).

Butler (2017) ainda destaca que mesmo que os sexos pareçam binários em sua morfologia e constituição, o que pode ser questionado tendo em vista as pessoas intersex ${ }^{2}$, por exemplo, "não há razão para supor que os gêneros também devam permanecer em número de dois" (2017, p. 26), visto que as identidades de gênero são múltiplas e crescem cada vez mais, assim como as identidades sexuais. Márcio Caetano defende que “a sexualidade não se ajusta a um modelo unívoco; ela é fundamentalmente plural” (2016, p. 159). Segundo o autor:

A sexualidade, no plano dos discursos regulatórios, é a estratégia social que permite controlar o desejo erótico. Em função dela, a cultura generaliza certos desejos eróticos e controla-os. A sexualidade não está determinada pelos imperativos biológicos, porém sujeita a condicionamentos sociais, culturais, históricos que se (auto) elaboram e se refletem na leitura dos imperativos biológicos sobre a e da vida. Isso não significa deixar se reconhecer a capacidade criativa do conhecimento biológico ou suas implicações na manutenção da vida (e da sexualidade como parte dela), mas a clareza que mesmo o biológico toma emprestado da cultura os significados inventados por ele. (2016, p.158)

A sexualidade é orientada pela lógica heteronormativa, ou seja, somos ensinados/as desde cedo que o "normal" e ou "natural" são os relacionamentos entre homens e mulheres, os demais são derivações que fogem ao padrão normativo vigente. A sexualidade ganha significado culturalmente, é através da cultura que somos ensinados/as a nos relacionar afetivamente e sexualmente, mas esta aprendizagem é condicionada a anatomia, logo, se uma pessoa nasce com um pênis, designada socialmente para ser do gênero masculino, habitualmente espera-se que esta se relacione com pessoas do gênero feminino, isto porque

2 "A reflexão queer sobre os intersex permite verificar não só como os processos de incorporação do gênero criam identidades binárias, baseadas em distinções férreas entre homens e mulheres, mas também como os processos sociais, criam, naturalizam o corpo num parâmetro binário" (PINO, 2007, p. 167). 
vivemos uma lógica heteronormativa, que prega uma coerência entre o corpo, o gênero e a sexualidade, mesmo que esta não dê mais conta da pluralidade de identidades que circulam. Apoiadas em Louro, salientamos que:

Atravessamentos das fronteiras de gênero e sexualidade parecem, hoje, mais frequentes, ou, quem sabe, talvez sejam simplesmente mais visíveis. $\mathrm{O}$ fato é que contemporaneamente, as classificações binárias de masculinidade e feminilidade ou de heterossexualidade e homossexualidade não dão mais conta das possibilidades de práticas e de identidades experimentadas pelos sujeitos. Isso não significa que se transite livremente entre esses territórios - por certo os guarda-fronteiras continuam vigilantes, severos e inflexíveis. (2017, p. 78)

Por mais que as identidades de gênero e sexuais estejam ganhando espaço e visibilidade, os discursos de ódio para com essas pessoas que afrontam as normas se propagam também, logo, a visibilidade não têm apenas efeitos positivos. A liberdade para ser o que é, é vigiada, controlada, como aponta a autora: "os guarda-fronteiras continuam ali vigilantes, severos, inflexíveis" (id., ibid.).

\section{LIBERDADE DE GÊNERO: APRESENTANDO O CORPUS E AS FERRAMENTAS DE ANÁLISE}

Este artigo teve como corpus de análise a primeira temporada da série Liberdade de Gênero, que estreou no dia 19 de outubro de 2016 e foi ao ar semanalmente nas quartas-feiras, as 21h30min, até 21 de dezembro de 2016, no canal GNT. A série mostra em 10 episódios como se organizam as vidas de 14 pessoas trans que assumem a realidade de ter um gênero diferente do sexo anatômico, trazendo exemplos em que essas pessoas se inserem de forma bem-sucedida e feliz dentro da sociedade. Na série, os/as entrevistados/as contam com a ajuda de familiares e amigos/as para narrarem as suas trajetórias.

Neste artigo, analisamos as falas dos/as entrevistados/as com relação às suas vivências de gênero e sexualidade. Para tal fim, utilizamos ferramentas da análise cultural, pois estas ferramentas nos possibilitam lançar olhares para as produções culturais. A autora Maria Lúcia Wortmann afirma que para a realização desse método de análise é importante “penetrar nas linguagens e garimpar os significados em uma multiplicidade de histórias e textos" (2007, p. 80). Para isso, os 10 episódios da série foram transcritos, as falas 
dos/as entrevistados/as foram analisadas, agrupadas por semelhanças e, a partir disso, elencamos eixos temáticos. Neste artigo, trazemos as análises referentes aos seguintes eixos: a) atributos de gênero; b) o entrelaçamento entre gênero e sexualidade; c) a mídia como um espaço de encontro e pertencimento.

\section{a) Atributos de gênero}

Neste eixo, nossas análises foram ao encontro das narrativas dos/as entrevistados/as sobre os atributos de gênero, relacionando às praticas sociais que desde cedo generificaram seus corpos, onde as diferenças anatômicas são tomadas para justificar determinadas práticas, comportamentos e condutas esperadas socialmente para cada gênero, sempre em número de dois, feminino ou masculino.

Butler nos provoca a pensar que os atributos de gênero não são expressões naturais, mas, sim, performativos:

Se os atributos de gênero não são expressivos, mas performativos, então constituem efetivamente a identidade que pretensamente expressariam ou revelariam. A distinção entre expressão e performatividade é crucial. Se os atributos e atos do gênero, as várias maneiras como o corpo mostra ou produz sua significação cultural, são performativos, então não há identidade preexistente pela qual um ato ou atributo possa ser medido; não haveria atos de gênero verdadeiros ou falsos, reais ou distorcidos, e a postulação de uma identidade de gênero verdadeira se revelaria uma ficção reguladora. (BUTLER, 2017, p. 243)

Sendo assim, as identidades de gênero não têm uma "essência" a ser expressa naturalmente, elas são produzidas e reproduzidas com o passar do tempo. A seguir analisamos as falas de algumas pessoas entrevistadas na série que mostram os conflitos entre os atributos de gênero esperados socialmente com suas identidades, evidenciando que o gênero é performativo, como nos propõe Butler (2017).

Quando a gente é criança não temos ainda na nossa cabeça a maldade, né? Eu era só uma criança brincando então me via daquele jeito e era assim que eu era. E aí fizeram um teste comigo, colocaram na minha frente um moletom do Mickey e um da Minnie, e mandaram eu escolher qual eu gostava mais. Como eu sempre gostei de rosa, é claro que corri pro da Minnie. E aí me falaram: Não! Tu não podes pegar esse moletom, esse moletom é de menina. Tu és um menino e tu vai ter que usar esse moletom [o do Mickey], Aí eu desabei no choro e foi aí o primeiro pensamento que eu tive: não, eu não sou uma menina, então eu tenho que agir de tal forma. (AMANDA)

O feminino nasceu comigo, roupas da mãe, o sapato de salto, tudo que tivesse uma simbologia associada ao feminino sempre gerava em mim um 
sofrimento. Eu entrava em loja de departamento masculino e essa parte não tinha nada que me interessava. Me mostravam um caminhãozinho e do lado uma boneca, eu queria a boneca. Mas você tem que brincar com o caminhãozinho, mas por que não com a boneca? (LETÍCIA LANZ)

Na infância eu achava que eu era um E.T., que eu era louco. O que aconteceu comigo, por que eu vim desse jeito? Essa percepção de que eu não era uma menina é desde que eu me entendo por gente, desde que eu me identifico como uma pessoa. No meu aniversário de 4 anos, a minha mãe colocou um tic tac no meu cabelo e beleza, eu continuei na festa, quando eu fui no banheiro e vi o tic tac na minha cabeça, acabou a festa. $O$ que os meus amigos vão pensar? Um menino de tic tac na cabeça? (ERICK)

Amanda se identifica como uma mulher transexual heterossexual, Letícia se identifica como uma transgênera lésbica e Erick se identifica como um homem transexual heterossexual. Suas falas trazem um ponto em comum: o desconforto com os comportamentos, com as brincadeiras e com as roupas determinadas para o gênero designado ao nascer despertou neles/as desde muito cedo, em suas infâncias. Situações como essas vigoram porque ao nascer um bebê, junto com ele nasce um conjunto de expectativas sociais que são estabelecidas a partir da genitália no nascimento, isto é, desde pequenos/as somos ensinados/as dentro da lógica heteronormativa que o nosso genital determina nosso gênero e que dependendo do gênero determinado, é preciso desempenhar determinados papéis e condutas que são esperados dentro da nossa sociedade.

Essa lógica heteronormativa é chamada de heteronormatividade, que de acordo com Petry e Meyer:

[...] visa regular e normatizar modos de ser e de viver os desejos corporais e a sexualidade De acordo com o que está socialmente estabelecido para as pessoas, numa perspectiva biologicista e determinista, há duas - e apenas duas - possibilidades de locação das pessoas quanto à anatomia sexual humana, ou seja, feminino/fêmea ou masculino/macho (2011, p. 195).

Ou seja, o sexo anatômico é um condicionante para definir o gênero e a sexualidade de uma pessoa, dentro dessa lógica heteronormativa. Diante dela, a história de Letícia, por exemplo, seria impensável, uma vez que Letícia nasceu com pênis, designada para ser homem e exibir atributos e condutas considerados do âmbito do masculino na nossa cultura; no entanto, se identifica com o feminino, se reconhece como uma mulher transgênera e se relaciona com outra mulher.

Letícia Lanz (2015), entrevistada na série, coloca que existe um condicionamento e 
adestramento sociopolítico-cultural que faz com que homens e mulheres consigam se reconhecer, se identificar e agir dentro da sociedade correspondendo às expectativas sociais. A autora nos provoca a pensar quando diz que a classificação de gênero é uma aposta da sociedade:

Cada vez que um bebê é classificado como homem ou como mulher, a sociedade faz uma aposta que, em função do seu órgão genital, de macho pênis - ou de fêmea - vagina -, o bebê irá se ajustar "como uma luva" na categoria de gênero masculino ou na de gênero feminino. Pra não perder a aposta, ainda no útero da mãe a sociedade começa a submeter o bebê a um intenso e exaustivo processo de adestramento/condicionamento para que ele efetivamente se torne homem ou mulher de acordo com a sua genitália: azul para meninos, rosa para meninas; bola de futebol para os meninos, boneca para as meninas. Depois que ele nasce o treinamento/condicionamento se intensifica e é exercida uma permanente vigilância social a fim da criança se comportar estritamente dentro da categoria de gênero em que foi classificada a nascer [grifos da autora] (2015, p. 137).

A partir da colocação da autora, percebemos que as falas dos/as entrevistados/as evidenciam apostas perdidas, visto que essas pessoas, desde a infância, não conseguem se enquadrar nas normas de gênero vigentes, por mais presentes que elas estejam em suas vivências através do controle que a família exerce, como é colocado nas falas. O controle para se manter no gênero determinado a partir da genitália é constante e se faz através da vigilância e das proibições: Isso não é coisa de menino/a! Meninos não choram! Sente-se como uma menina! São algumas sentenças, construídas dentro da lógica heteronormativa, que vão agenciando essas identidades e que castigam aquelas que fogem aos padrões.

A autora Berenice Bento afirma que:

Os brinquedos, as cores das roupas e outros acessórios que comporão o enxoval são escolhidos levando-se em conta o que seria mais apropriado e natural para uma vagina e um pênis. No entanto, como é possível afirmar que todas as crianças que nascem com vagina gostam de rosa, de bonecas, de brinquedos que não exigem muita força, energia e inteligência? Aquilo que evocamos como um dado natural, o corpo-sexuado, é resultado das normas de gênero. Como afirmar que existe um referente natural, original, para se vivenciar o gênero, se ao nascermos já encontramos as estruturas funcionando e determinando o certo e o errado, o normal e o patológico? O original já nasce "contaminado" pela cultura. Antes de nascer, o corpo já está inscrito em um campo discursivo. (2011, p. 550)

A existência de pessoas trans atua no sentido de desconstruir essas produções culturais que são dadas como naturais, colocando em xeque a existência do gênero masculino ou feminino atrelada ao sexo anatômico, deslocando essas "verdades" do 
determinismo biológico. Tais experiências evidenciam que o gênero não é dependente do sexo anatômico. Essas questões precisam ser desconstruídas "para se desmistificar o trabalho refinado que o sistema heterossexual processa ao produzir uma masculinidade e uma feminilidade naturalizadas e aprisionadas na lógica de um determinismo biológico" (PAMPLONA; DINIS, 2017, p. 03).

\section{b) "Sexo genital está entre as pernas, gênero está no cérebro e orientação}

\section{sexual está entre os braços": entrelaçamento entre gêneros e sexualidades}

A puberdade parece ser um período ainda mais conflitante do que a infância, nesta etapa o corpo parece caminhar para o lado errado do que eles/as gostariam e a sexualidade

passa também a ser um incômodo. É na puberdade que as mudanças hormonais desencadeiam as mudanças físicas e o conflito com o gênero com o qual se identificam aparece com mais intensidade. Alguns relatam que antes de conhecerem o que era a transexualidade se reconheciam como gays, mas mesmo assim sentiam que algo estava errado, porque não conseguiam se relacionar com pessoas do "mesmo" sexo.

Tinha alguma coisa errada, porque eu não conseguia me ver ficando com outro menino sendo menino. Eu não sou gay, eu sou uma mulher trans heterossexual. Eu não me aceitava no corpo de homem, então essa condição homossexual pra mim não funcionava. (AMANDA)

$\mathrm{Na}$ adolescência foi um pouco mais difícil, porque eu conheci outros meninos que eram gays, mas eu não me identificava com eles, eu pensava: eu não sou isso! Eu queria ser como a minha irmã, como a minha mãe, como as minhas amigas. (CAROL)

Eu sempre gostei de meninas e eu me apaixonei por meninas quando eu tinha nove anos mais ou menos, só que pra mim era impensável, eu não queria nem chegar perto. Minha adolescência foi muito difícil, porque caiu no meu colo que eu era uma lésbica e que eu ia ter que viver nesse corpo. (ERICK)

Esse entrelaçamento entre gênero e sexualidade parece ser comum nas vivências dos/as entrevistados/as, pois a maioria relata que enquanto desconhecia a possibilidade de ser transexual, travesti ou trans não binário as relações homossexuais pareciam não ter sentido. O sentimento de não se reconhecer enquanto homossexuais, faz jus ao entrelaçamento que existe entre gênero e sexualidade, eles/as sabiam que algo não estava de acordo, mas, não era em relação à sexualidade, e sim com o corpo, a sensação era de não se reconhecer ao gênero designado. A mudança que eles/as desejavam não era em relação à orientação sexual, mas, 
sim que seus corpos se ajustassem a identidade de gênero a qual eles/as sentiam pertencer e que assim, seus corpos the garantissem a inteligibilidade social esperada.

Márcia e Letícia são duas das entrevistadas que fogem a esse padrão. Márcia sempre gostou de meninas e se considera uma travesti lésbica e Letícia é casada há mais de 40 anos com a mesma mulher e se considera uma transgênera lésbica, inclusive, ambas relatam que são criticadas por sua sexualidade, uma vez que como se identificam com o feminino deveriam - dentro da lógica heteronormativa - gostar de homens. Casos como estes relatam que a sexualidade está deslocada de qualquer determinismo biológico. A autora Berenice Bento traz essa questão:

Quando uma pessoa diz "Eu tenho um corpo equivocado, sou um/a homem/mulher aprisionado/a em um corpo de mulher/homem", isto não significa que ser mulher seja igual a ser heterossexual. Quando a sociedade estabelece que o/a homem/mulher de verdade é heterossexual, deduz-se imediatamente que um/a homem/mulher transexual deverá sê-lo, e são construídos dispositivos em torno dessa realidade. (2006, p.156)

A partir desta citação da autora e das falas dos/as entrevistados/as no programa, percebemos que a identidade de gênero de um homem trans ou de uma mulher trans é questionada, ainda mais, quando estes/as não se enquadram ao padrão heterossexual, sinalizando que a condição heterossexual está intimamente ligada ao reconhecimento de um/a homem/mulher de "verdade".

Ana Carolina, namorada de Márcia, conta que enquanto namorava com mulheres lésbicas, a sociedade entendia isso como "comum", mas que a partir do momento em que hoje ela se apresenta namorando uma travesti, as pessoas questionam, inclusive as lésbicas: mas, espera um pouco, você não é lésbica?

Isso se justifica porque dentro da sociedade heteronormativa em que vivemos, até dentro da própria comunidade LGBT (Lésbicas, Gays, Bissexuais, Travestis, Transexuais e Transgêneros), as pessoas devem se enquadrar às normas estabelecidas. O conservadorismo da sociedade reflete na comunidade, enquanto nela deveria encontrar resistência e novas formas de pensar os gêneros e as sexualidades. Conforme Berenice Bento, as expressões de gênero, as sexualidades, as subjetividades só apresentam uma correspondência com o corpo quando é a heteronormatividade que orienta o olhar (BENTO, 2014, p. 53).

Além disso, Márcia conta que sempre gostou de meninas! E pergunta para a mãe: 
Namorei um pouquinho, né? (Márcia) E a mãe responde: Bastante, é isso que a gente não entende, se veste de mulher, devia gostar de homem. (Dora, mãe de Márcia)

Wallace se identifica como uma pessoa trans não binária e conta sobre um episódio engraçado com relação ao entendimento da sua mãe sobre a sua sexualidade, que vai ao encontro da fala da mãe de Márcia. Ele diz:

[...] até um caso engraçado, sobre isso de sexualidade, que recentemente eu tive um caso com uma garota, aí a minha mãe falou assim: ah, não, pera! Primeiro você é menino, agora você é menina, primeiro você é gay, agora você é lésbica?! Não tô entendendo! Eu não consigo, para! Orientação sexual tá relacionada para quem eu oriento o meu desejo. A identidade de gênero tá relacionada ao entendimento, como você se entende, se como mulher ou como homem. (WALLACE)

Novamente a lógica da heteronormatividade aparece nas falas, demonstrando que socialmente costuma-se fazer um entrelaçamento entre gênero e sexualidade, embora sejam coisas distintas. Isso porque se espera que haja um regime de inteligibilidade entre corpo, gênero e desejo, de modo que se o sujeito assume um gênero masculino, ainda que tenha uma vulva, espera-se que ele se relacione afetiva e sexualmente com mulheres.

Para Berenice Bento:

A existência trans põe em destaque aqueles atos discursivos e corporais considerados socialmente importantes para dar vida aos corpos-sexuados, ao mesmo tempo em que os desloca. Se a experiência nega a origem biológica para a explicação dos comportamentos, contraditoriamente, é a pressuposição dessa origem natural que gerará as expectativas e as suposições sobre as condutas apropriadas para os gêneros. Suas histórias interrompem a linha de continuidade e de coerência que se supõe natural entre corpo, sexualidade e gênero, ao mesmo tempo em que apontam os limites da eficácia das normas de gênero e abrem espaços para produção de fissuras que podem, potencialmente, transformar-se em contradiscursos e libertar o gênero do corpo-sexuado. (2014, p. 63)

A existência trans põe em xeque não só a naturalidade dos gêneros pautada no determinismo biológico, mas, também, da sexualidade condicionada ao gênero. Sendo assim, rompe com a inteligibilidade do corpo- gênero-desejo, histórias como a de Márcia e Letícia evidenciam que nem toda mulher tem vagina e deseja ter relações com homens, embora exista uma expectativa social criada a partir de um determinismo biológico. A autora Judith Butler problematiza este regime de inteligibilidade entre corpo, gênero e desejo quando expõe: 
Gêneros inteligíveis são aqueles que, em certo sentido, instituem e mantêm relações de coerência e continuidade entre sexo, gênero, prática sexual e desejo. Em outras palavras, os espectros de descontinuidade e incoerência, eles próprios só são concebíveis em relação a normas existentes de continuidade e coerência, são constantemente proibidos e produzidos pelas próprias leis que buscam estabelecer linhas causais ou expressivas de ligação entre o sexo biológico, o gênero culturalmente constituído e a "expressão" ou "efeito" de ambos na manifestação do desejo sexual por meio da prática sexual $(2017$, p. 43$)$.

Sendo assim, o gênero adquire inteligibilidade através do sexo que, consequentemente, determina também, o desejo, de acordo com a lógica heteronormativa. A construção de uma coerência entre o sexo-gênero-desejo faz com que as identidades de gênero divergentes ao padrão, como as experiências trans, sejam impensadas dentro do regime de heteronormatividade compulsória em que vivemos. Porém, essas experiências produzem fissuras na lógica heteronormativa e fazem emergir outras identidades de gênero e sexuais que tensionam os limites dessas normas.

Por exemplo, Lune, Jesse e Benett se consideram pessoas trans não binárias que se aproximam mais do masculino. Eles colocam que são pansexuais e que a sexualidade os levou a se reconhecerem enquanto pessoas trans não binárias, porque de acordo com eles, a pansexualidade está ligada a essa identidade de gênero. Com relação a isso, são questionados por João, diretor da série:

\section{O que é pansexual? (JOÃO)}

Basicamente uma pessoa que gosta de outras pessoas, independente de gênero ou do que elas têm no meio das pernas. A pansexualidade me levou a conhecer a identidade de gênero não binária. Uma coisa tá meio que ligada a outra, assim, meio que um combo. Se eu não me identifico com nenhum gênero, eu não espero escolher nenhum desses gêneros pra ficar. (LUNE)

Bennet e Jesse complementam a fala sobre a orientação sexual, dizendo:

Eu não gosto das pessoas pelo gênero, eu gosto das pessoas porque são pessoas. (BENETT)

Eu geralmente gosto de pessoas mais andróginas, justamente por elas não serem tão cis, mas isso é uma questão de gosto, também eu não me limito. Tanto no gênero quanto na orientação eu não vou me limitar, me prender a nada. É bem simples. Bem mais simples do que parece. (JESSE)

Essas identidades de gênero e sexuais são possíveis de existir hoje graças a outras que vêm subvertendo com o regime de inteligibilidade corpo-gênero-desejo, provocando 
fissuras no sistema heteronormativo. De acordo com o autor Leite Jr., as existências trans ingressam no campo político "não só fazendo-nos questionar sobre o que é real e o que deve sê-lo, mas também mostrando-nos como as ações contemporâneas de realidade podem ser questionadas e como novos modos de realidade podem ser instituídos" (2008, p. 126-127). Ou seja, é questionando as formas de se viver os gêneros e as sexualidades, que outras e novas formas de vivencia-los podem ser instituídas.

Guacira Louro (2017) nos instiga a pensar nas identidades de gênero que não se definem nem com o masculino e nem com o feminino, reivindicando para si uma não binariedade, quando coloca:

Assim como em outros territórios, também nos territórios de gênero e sexualidade há aqueles e aquelas que vivem na própria fronteira. Sujeitos que não chegam a completar o cruzamento e vivem a ambiguidade do entre-lugar. Por vezes, esses sujeitos inscrevem em seus corpos as marcas dos dois lados, confundindo quem os encontra, ou escapam de um lado para outro, não se deixando fixar, deslizando. (2017, p. 80)

Em torno disso, refletimos o quanto é importante ouvir o que as pessoas têm a dizer sobre si mesmas, assim como é mostrado na série Liberdade de Gênero. Existem possibilidades diversas de vivenciar os gêneros e as sexualidades, de maneira a tensionar as normas impostas, contribuindo para que fissuras sejam expostas nesse cistema ${ }^{3}$ que reduz as vivências ao binômio de gênero.

c) "Essa sensação de encontrar alguém como você, é uma das melhores do mundo": mídias, espaço de encontro e pertencimento

As histórias analisadas também apontam os espaços das mídias como espaços de encontros e pertencimento, onde essas pessoas se encontram consigo mesmas e demarcam pertencimento a um grupo, no que diz respeito às vivências de gênero e sexualidade. Nesses espaços, elas puderam se reconhecer enquanto sujeitos trans a partir de referências diversas, como através de uma personagem de novela no caso de Dani, através de uma história vivenciada por um personagem que se considerava transexual em um filme que também aborda a temática da transexualidade, como no caso de Erick, em grupos no Facebook de pessoas trans, como a história de Oliver, ou até mesmo com a identificação com personagens de jogos de videogame que eram transexuais, como é o caso de Amanda.

\footnotetext{
${ }^{3}$ A ativista e pesquisadora trans Viviane Vergueiro (2015) utiliza a palavra cistema, corruptela de "sistema", com a intenção de denunciar a existência de cissexismo e transfobia no sistema social e institucional dominante.
} 
Dani diz:

[...] com 12 anos, eu me lembro de ter assistido a novela da Ramona, que era interpretada pela atriz Claudia Raia, e que mesmo com os vícios da novela, conseguiu tratar de forma sensivel à questão da transexualidade. Eu fiquei louca, eu pensei: meu Deus, é isso, então! Eu tive plena certeza que precisava passar por aqueles procedimentos para me encontrar. (DANI)

Erick fala que:

[...] quando estreou o filme Meninos não Choram ${ }^{4}$ eu quis assistir a todo custo. Foi um tapa na minha cara, eu pensei: eu sou isso aí. E aí eu chorei por 20 anos acumulados, eu entendi que eu era transexual, que existia um caminho pra percorrer e eu queria tudo pra ontem. Essa sensação de encontrar alguém como você, é uma das melhores do mundo, eu pensei que não estava sozinho no mundo. É uma sensação de pertencer, sabe? (ERICK)

Oliver relata:

Em algum momento eu conheci pessoas trans pela internet e assim soube da existência, na verdade, e aí quando eu descobri isso, fui pra um grupo de pessoas trans no Facebook, que era só de gente trans não binária e foi aí que eu comecei a ver e a me entender como trans mesmo. (OLIVER)

Amanda, mesmo quando ainda desconhecia o que era transexualidade, já se montava para eventos como anime $e^{5}$ e nesses eventos se identificava como Amanda. Mas, ela conta:

[...] aos 17 anos eu fiz um amigo, a gente se adicionou no $\mathrm{msn}^{6}$ depois de um tempo eu vi que ele tinha mudado o nome dele pra Luna. Então, eu perguntei: Por que teu nome tá Luna? E ele: ah, porque eu sou transexual. E eu: hãa? O que é isso? Aí ela começou a me explicar sobre o que ela sentia, sobre disforia de gênero, que ela estava indo em psiquiatras, em psicólogos, estava começando a transição e aí eu pensei: Nossa! É aí que eu me encontro! É aí que eu me encaixo, eu não sou um menino gay, eu sou uma mulher transexual. (AMANDA)

Em torno dessas falas, percebemos que as mídias atuam, hoje, como mais uma referência, um espaço privilegiado onde circulam informações sobre os sujeitos e sujeitos que antes não tinham a visibilidade que apresentam agora, como as pessoas trans.

\footnotetext{
${ }^{4}$ De acordo com a sinopse, o filme Meninos não Choram conta a história de Teena Brandon que se tornou Brandon Teena e passou a reivindicar uma nova identidade, masculina, numa cidade rural de Falls City, Nebraska. Brandon inicialmente consegue criar uma imagem masculinizada de si mesma, se apaixonando pela garota com quem sai Lana, e se tornando amigo de John e Tom. Entretanto, quando a identidade sexual de Brandon vem público, a revelação ativa uma espiral crescente de violência na cidade.

${ }^{5}$ Anime são animações japonesas de jogos de videogame, onde têm personagens transexuais.

${ }^{6}$ MSN é um portal online de mensagens instantâneas e de serviços da empresa Microsoft, lançado no ano de 1995.
} 
As mídias estão promovendo outras relações com o público, endereçando-se a sujeitos trans, por exemplo, ensinando "outros" modos de ser e de entender esses corpos, atuando como uma pedagogia cultural, como um espaço onde essas pessoas podem se ver representadas e por isso um espaço de encontro e pertencimento.

Entendemos, a partir da perspectiva pós-estruturalista, que a "representação se expressa por meio de uma pintura, de uma fotografia, de um filme, de um texto, de uma expressão oral". (SILVA, 2005, p. 4) E vemos isso exposto nas falas, quando, por exemplo, Erick fala "eu sou isso aí. [...] eu entendi que eu era transexual.” Erick, por exemplo, identificou-se com o personagem transexual no filme que assistiu e então passou a conhecer o que era transexualidade, assim como Amanda, que diz: "É aí que eu me encontro! É aí que eu me encaixo, eu não sou um menino gay, eu sou uma mulher transexual". Nos excertos, percebemos que Erick e Amanda, assim como Oliver e Dani, reconhecem suas identidades através das representações presentes nesses artefatos culturais. O autor Tomaz Tadeu da Silva coloca que:

A identidade e a diferença são estreitamente dependentes da representação. É por meio da representação, assim compreendida, que a identidade e a diferença adquirem sentido. É por meio da representação que, por assim dizer a identidade e a diferença passam a existir. Representar significa, neste caso, dizer: "essa é a identidade", "a identidade é isso". (2005, p. 91)

Nesse contexto, eles/elas ao virem representada a identidade trans reconhecem a sua identidade "eu sou isso" e a partir de então essa adquire sentido. Dessa forma, se estabelece possibilidades de identidades de gênero que escapam ao determinismo reducionista do sistema sexo-gênero, como coloca o autor Claudio Alves e a autora Maria Ignez Moreira: “sujeitos ambivalentes e não adequados aos olhos do senso comum, que se diluem numa polissemia de relações nas quais sexo, gênero, corpo e desejo se combinam, se recombinam ou, ainda, não se combinam” (2014, p. 13).

\section{ALGUMAS CONSIDERAÇÕES}

A série Liberdade de Gênero deu visibilidade para a diversidade de identidades de gêneros e sexuais, informando sobre o tema e (re)produzindo modos de ser "diferentes" do qual adotamos como "naturais", desconstruindo "verdades" sobre os gêneros, sobre os sexos e sobre as sexualidades. A série nos ensina sobre outros modos de ser e estar 
no mundo uma vez que somos educados/as através de diferentes meios, dentre os quais os programas televisivos.

Neste artigo problematizamos sobre os gêneros e seus atributos, propondo que estes sejam pensados em suas múltiplas possibilidades, evidenciando suas pluralidades, sem estar aprisionado a um determinismo biológico que reduz essa experiência ao binômio feminino/masculino, mulher/homem, fêmea/macho. Podemos afirmar que não existe o masculino e o feminino original, esses são produzidos culturalmente de acordo com as normas de gênero que regem cada cultura, tempo e lugar, legitimando assim modos de ser mulher e modos de ser homem.

No tempo em que vivemos a diferença se multiplicou e a verdade é plural, como nos instigou a autora e fundadora do GEERGE Guacira Louro (2003), assim, não cabe mais essa divisão binária, reforçada por uma heteronorma que nos é reiterada a todo tempo, denunciando o seu caráter questionável. Compreender os gêneros e as sexualidades como construções sociais, culturais, históricas atravessadas por relações de poder, nos faz compreender como determinadas práticas foram sendo naturalizadas e consideradas mais legítimas do que outras e, assim, questioná-las.

As narrativas dos/as entrevistados/as que analisamos dissolvem a lógica entre sexo, gênero e desejo, embaralhando a fixidez das "verdades" sobre eles que nos são dadas, atribuídas de forma essencializada. De acordo com a lógica heteronormativa que vivemos, histórias como as discutidas neste artigo, denunciam o quanto a sexualidade vinculada ao gênero é uma construção, já que existem múltiplas formas de vivenciar as sexualidades.

No nosso tempo de constantes transformações culturais, destacamos, também, a importância das mídias. Nas falas percebemos esta instância como um espaço de encontro e pertencimento, onde as pessoas se reconhecem enquanto trans ao conhecer essas identidades expostas em algum artefato cultural, como: um grupo no Facebook, uma novela, um filme.

Por fim, colocamos que nossa pretensão não é definir ou essencializar qualquer expressão identitária, por entendermos que as experiências trans são diversas, múltiplas e plurais, são experiências que fogem ao padrão vigente de gênero, de sexualidade e de corpo e não se encaixam a uma sintetização homogênea. 


\section{REFERÊNCIAS}

ALVES, Cláudio Eduardo Resende; MOREIRA, Maria Ignez Costa. (Trans)narrativas de fronteira. Disponível em https://periodicos.ifrs.edu.br/index.php/tear/article/viewFile/ 1825/1426. Acesso em: 10 de set. 2018.

BENTO, Berenice. A reinvenção do corpo: sexualidade e gênero na experiência transexual. Rio de Janeiro: Gramind, 2006.

$\mathrm{Na}$ escola se aprende que a diferença faz a diferença. Estudos Feministas, v. 19, n. 2, ago. 2011. p. 549-559.

- O que pode uma teoria? Estudos Transviados e a Despatologização das Identidades Trans. In: Florestan, n. 2, p. 46, 2014.

BUTLER, Judith. Problemas de Gênero: Feminismo e Subversão da Identidade. Rio de Janeiro: 13a ed. 2017.

CAETANO, Marcio. Performatividades reguladas: heteronormatividade, narrativas biográficas e educação. Curitiba: Appris, 2016.

COSTA, Marisa Vorraber. Estudos Culturais: para além das fronteiras disciplinares. In:_ (Org.) Estudos Culturais em Educação: mídia, arquitetura, brinquedo, biologia, literatura, cinema. Porto Alegre: Editora da UFRGS, 2004. p. 13-36.

ESCOSTEGUY, Ana Carolina. Estudos Culturais: uma introdução. O que é, afinal, Estudos Culturais? 3. ed., Belo Horizonte: Autêntica, 2004. p. 133-166.

HALL, Stuart. A centralidade da cultura: notas sobre as revoluções do nosso tempo. Educação \& Realidade, Porto Alegre, v. 22, n. 2, p. 15-46, jul./dez. 1997.

LANZ, Letícia. O corpo da Roupa: Uma introdução aos Estudos Transgêneros Movimento Transgente, 2015.

LEITE JR, Jorge. Nossos corpos também mudam: a invenção das categorias "travesti" e "transexual" no discurso científico. Tese de Doutorado em Ciências Sociais apresentada à Pontífica Universidade Católica de São Paulo. São Paulo: PUC - SP, 2008.

LOURO, Guacira Lopes. Corpos que escapam. Estudos feministas, v. 4, n. 4, 2003

. Gênero e sexualidade: pedagogias contemporânea. Pró-Posições, Campinas, v. 19, n. 2, p.17-23, maio/ago. 2008.

Flor de açafrão: takes, cuts, close-ups. Belo Horizonte: Autêntica, 2017.

PAMPLONA, Renata Silva; DINIS, Nilson Fernandes. A transexualidade em questão: problematizações nos contextos educacionais. Itinerarius reflectionis (online), v. 13, p. 1-24, 2017.

PETRY, A.R; MEYER, D.E.E. Transexualidade e hetoronormatividade: algumas questões para a pesquisa. Textos e contextos. Porto Alegre, v.10, n.1, p.193-198, jan/jul.2011.

PINO, Nádia Perez. A teoria queer e os intersex: experiências invisíveis de corpos des-feitos. Cadernos Pagu, v. 28, n. 5, p. 149-174, 2007.

SILVA, Tomaz Tadeu da. A produção social da identidade e da diferença. In: HALL, Stuart; WOODWARD, Kathryn; SILVA, Tomaz Tadeu da (Org). Identidade e diferença: a perspectiva dos estudos culturais. Editora Vozes, 2005. 
- Documentos de identidade: uma introdução às teorias do currículo. Belo Horizonte: Autêntica, 2007.

VEIGA-NETO, Alfredo. Dominação, violência, poder e educação escolar em tempos de império. In: RAGO, Margareth; VEIGA-NETO, Alfredo (Org.). Figuras de Foucault. Belo Horizonte: Autêntica, 2006. p. 13-38.

VERGUEIRO, Viviane. Por inflexões de corpos e identidades de gênero inconformes: uma análise autoetnográfica da cisgeneridade como normatividade. 2015. Dissertação. Universidade Federal da Bahia, Instituto de Humanidades, Artes e Ciências Porfessor Multon Santos. Salvador, 2015.

XAVIER FILHA, Constantina. Gênero, sexualidade e diferença em livros para a infância. In: MAGALHÃES, Joanalira Corpes; RIBEIRO, Paula Regina Costa (Org.). Educação para a sexualidade. Rio Grande: Editora da FURG, 2014. p. 231-246. (Coleção Cadernos Pedagógicos da EAD, v. 23).

WORTMANN, Maria Lúcia. Análises Culturais. In: COSTA, Marisa Vorraber (Org.). Caminhos Investigativos II: outros modos de pensar e fazer pesquisa em educação. 2 ed. Rio de Janeiro: Lamparina, 2007. p. 71-90. 